ISBN 978-981-14-1684-2

Proceedings of 2019 the 9th International Workshop on Computer Science and Engineering

(WCSE 2019 SUMMER)

Hong Kong, 15-17 June, 2019, pp. 52-58

doi: $10.18178 /$ wcse.2019.06.009

\title{
The Extended Mobile Health Acceptance Model in Thailand: A Conceptual Framework
}

\author{
Paneepan Sombat, Wornchanok Chaiyasoonthorn ${ }^{+}$and Singha Chaveesuk ${ }^{+}$ \\ Faculty of Administration and Management King Mongkut's \\ Institute of Technology Ladkrabang, Bangkok, Thailand
}

\begin{abstract}
Information technology has revolutionized people's lifestyle. People have the liberty of using the smart technology for reapings its benefits especially related to health care. The government of Thailand wants to optimize its benefit with the adoption of this technological advancement in the field of health care service in line with Thailand industry 4.0 policy and digital economy. Mobile health is one of the steps in this direction. However, less people in Thailand have performed on using mHealth services and limited research has been found under the acceptance of using mHealth technology. This study will help establish links to the general public and their accessibility and the ways to increase the usage rate. The mHealth acceptance framework is developed by integrating the Unified Theory of Acceptance and Use of Technology combined with self-efficacy, technology anxiety, and personal innovativeness in information technology. The contribution of this study is to build a proposed model for the mHealth acceptance and its use in Thailand.
\end{abstract}

Keywords: mHealth acceptance, UTAUT, Self-efficacy, Technology anxiety, Personal innovativeness in information technology.

\section{Introduction}

Due to ease of use and user-friendly interface as technological advancements in information technology (IT), there is a growing trend of use of modern mobile health on smart mobile phones [1]. mobile health service (mHealth) has gained more attention in the recent years [2]. mHealth is an innovative technological system that works on a portable computer in the medical field. The remarkable notice includes the popular use of mobile phone technology for health care [3]. For example, information about the patient's medical history will be recorded in the system such as medical tests, treatments, medicines, and additional observations recorded by doctors for their patients, or patients' health [4]. The potential benefits of mHealth services include the obtainability of more effective health care as well as the instant consultation by the doctors. mHealth correspondingly helps to increase the various perspectives of health care such as helping patients and service providers to exchange messages and also accessible the exchange correspodence on websites. It can also support clinical decisions by allocating data and applications focusing on health taking into account of the patients' residence and other relevant information associated with him/her [5][6][7][8]. The records illustrates that upto 165,000 applications have been downloaded in context mHealth and has market industry of generating $\$ 10.2$ billion. Therefore, mHealth poses as a strong tool in terms of health care, behavior improvement and has been widely recognized around the world [9][10][11][12].

In Asian countries including: Malaysia, Singapore, Indonesia, India, or Thailand has brought legislations promoting the use of technology to solve medical and healthcare complications [13]. Specifically in Thailand, the Ministry of Public Health has continuously being restructured and maintaining the best health information system status for several years [14][15]. The goal is to mandate a strong information system

\footnotetext{
+ Corresponding author. Tel.: + 6691533845; + 6696925424; fax: +663298461.

E-mail address: wornchanok.ch@kmitl.ac.th; singha@it.kmitl.ac.th.
} 
covering health information at the village level and community health center (CHC) using innovative healthcare technology such as mHealth [14][16]. Although mHealth plays an important role of health services and provides variety of benefits to help treating medical problems on smartphones [17]. On its contrary, it has been also noted that very few people recognizes its adoption [18].

To encourage people in adoption of mHealth, patients are required to realize its values or benefits obtained from the innovative systems. mHealth acceptance might depend on different factors such as the degree of perception behavior and attitude towards the user friendly design as well as the anti-anxiety in using technology that could increase the acceptance and the willingness of service users [19]. The aim of this study is to build a conceptual framework based on The Unified Theory of Acceptance and Use of Technology (UTAUT) to initially investigate the factors influencing technology adoption among clients for hospitals through mHealth. In addition, self-efficacy (SE), technology anxiety (TA), and personal innovativeness in information technology (PIIT) have been included as the indicators.

\section{Theoretical Foundations}

The previous studies has revealed that UTAUT has been usually recognized and widely used to examine the acceptance and the behavior of mHealth's users [19][20]. Venkatesh et al., (2003) describes UTAUT's ability to measure the influence of information technology on user behavior and acceptance [21]. The UTAUT model is generally dominated by four main constructs: Performance Expectancy (PE) that further consists of 4 dimensions which can highlight the complete structure including (increased productivity, increased work efficiency, working efficiency, and helpfulness). Social influence (SI) also further comprises of 3 constructs which include (intend to use, predict to use, and plan to use). Facilitating Conditions (FC) further consists of 3 constructs of operationalization which include (necessary knowledge to use, necessary resources to use, and available assistance), and Effort Expectancy (EE) further consists of 3 constructs including clear and understandable, skillful at using, easy to use[21][22][23].

For example, Zhou et al., (2016) used UTAUT to study the use of eHealth systems in Zimbabwe [24]. Moreover, Boonchai et al., (2009) have modified the UTAUT to study the acceptance of IT health in community health centers in Thailand [25]. In addition, UTAUT has been considered to develop and examine user acceptance arrangements and the use of new technologies [26][27]. Venkatesh et al., (2003) believed that UTAUT helps in predict the user's intention to use of new technology [28]. It seems that previous studies observed that UTAUT model has been mostly used to create a structure of acceptance in health care [18] and much research indicated that UTAUT is widely used in electronic health and mHealth to study usage behavior of technology acceptance combined with additionally different contexts. Moreover, UTAUT can explain the 70\% of variance in its worldwide use [28][29][30].

This UTAUT is appropriate to use for examining mHealth acceptance in order to investigate relationships among the constructs of user acceptance [26]. According to Venkatesh et al., (2003), the causal relationships among technological users' acceptance and actual usage was studied by indicating external variables; the result of empirical research postulated that the UTAUT was a better model of technological acceptance when compared with the existing model determined by PE, EE, SI and FC as shown in Fig. 1. Therefore, UTAUT model is used as a comprehensive examination of mHealth acceptance.

\section{Hypothesis Development}

Based on the previous studies on UTAUT theory, it shows that it is one of the most well-known and widespread form of human behavior study focusing on user acceptance, especially in mHealth and this could increase the value of providing mobile healthcare system acceptance [31][32]. The UTAUT model acts as a functional tool as a behavioral determinant and control. The UTAUT model is applied to examine the use of eHealth system and to consider the factors influencing the intention use of eHealth or mHealth in health clinical practice [24][33][34].

Thus, UTAUT is used as a theoretical instrument which can mainly predict new information technology adoption. The extended UTAUT has been proposed with seven constructs: 1) Performance Expectancy (PE), 2) 
Social Influence (SI), 3) Facilitating Conditions (FC) 4) Effort Expectancy (EE), 5) Self-Efficacy (SE), 6) Technology Anxiety (TA) and 7) Personal Innovativeness in Information Technology (PIIT).

Firstly, Performance expectancy (PE) is characterized as intention and behavior at the level where each person believes that using technology systematically will help him or her to acquire work performance. PE explains the expectations of mHealth performance due to the degree at which each person believes that using an alternative health care system will contribute to overall efficiency [35]. Previous studies found that PE increased as a result of increased intention to use the technology [27]. In addition, Or et al., (2011) found that PE significantly influenced intention and acceptance behavior [36]. Thus, this hypothesis is generated as:

H1: PE has a positive influence on behavioral intention in using mHealth.

Secondly, Social Influence (SI) refers to the awareness level of individual who believes that he/she should use IT systems for health care [36]. According to Hoque \& Sorwar (2017), it was considered as "The level at which individual perceives that other people believe he or she should use the new system" [19].

SI has been a strong impact on users' intention to adopt technology [37]. In addition, other studies have found that SI influences user behavior and commitment to the use of digital information in healthcare [38]. Thus, the second hypothesis is proposed as:

H2: SI has a positive impact on behavioral intention in using mHealth.

Next, Facilitating Conditions (FC) is explained as the degree to which each individual believes that organizational and technical infrastructure exists to support the use of the system [25]. Specifically, a study by Akhtar et al., (2017b) has especially applied IT to skills in knowledge of resources and other infrastructure to facilitate the operation of the user [39]. Consequently, users could be more motivated to adopt IT resulting in increased use of technology intentions and actual use [40]. The next hypotheses are developed as:

$\mathrm{H} 3$ : $\mathrm{FC}$ has a positive influence on behavioral intention in using mHealth.

H4: FC has a positive influence on actual use in using mHealth.

Effort Expectancy (EE) describes as the effort or simplicity, the most important element in the use of IT. It often influences on the intention of using IT. EE is defined as "the degree of ease associated with the use of the system" [41]. Moreover, Prasnna \& Huggins, (2016) found that the willingness to use technology is influenced by experience and skill, system compatibility, and ease of use [42]. Therefore, this hypothesis is proposed as:

H5: EE has a positive influence on behavioral intention in using mHealth.

Behavior Intention (BI) is used and applied to explain "the degree to which a person has formulated conscious plans to perform or not to perform some specified future behavior" [27]. Kijasanayotin et al. (2009) found that behavioral intention has an influence on actual use of health information technology. It also relates to other factors such as attitudes. BI has been determined to influence on the actual use of technology in different intention models [43].

H6: BI has a positive influence on actual use in using mHealth.

Self-Efficacy (SE) has been measured as individual's perceived ability to use mHealth for the purpose of health management. SE examined by Kim \& Park (2012) significantly and indirectly shows the influence on intention to use via performance expectancy [44][45]. Therefore, SE positively influenced PE on the use of mHealth [44]. and the seventh hypothesis is as follows:

H7: SE has a positive influence on performance expectancy in using mHealth.

Technology Anxiety (TA) is defined as a negative emotional response and a feeling of fear when using technology [46]. Prior studies used the TA construct and applied to explain technology concern as a negative relation, such as emotional response, fear or discomfort, and experience when thinking about using or using technology [47][48]. Thus, the next hypothesis is generated as follows:

H8: TA has a positive influence on behavioral intention in using mHealth.

Personal Innovativeness in information technology (PIIT) describes as "the willingness of an individual to try out some new information technology" [49]. The study of Roger, (1995) found that the individual's advanced perception and acceptance, which initiate from one's ability to perform tasks with technology, resulting in the increase of acceptance level and the tendency to rely on technology. It also stated that each PIIT influences 
through the processes and decisions, and noted that PIIT can moderate individual IT perception and their behavioral intentions. In addition, it assumed that people who are able to have PIIT often use more IT facilities because they have less anxiety [50]. With this, EE is a measurement of the level of ease of the system. EE has influenced the intention and acceptance of the use of health information systems. Therefore, it poses a strongly relation between understanding of the technology characteristics in terms of $\mathrm{EE}$ and behavioral determination to adoption IT [49]. The next hypotheses are as follows:

H9: PIIT has a positive impact EE on behavioral intention in using mHealth.

H10: PIIT has a positive impact on behavioral intention in using mHealth.

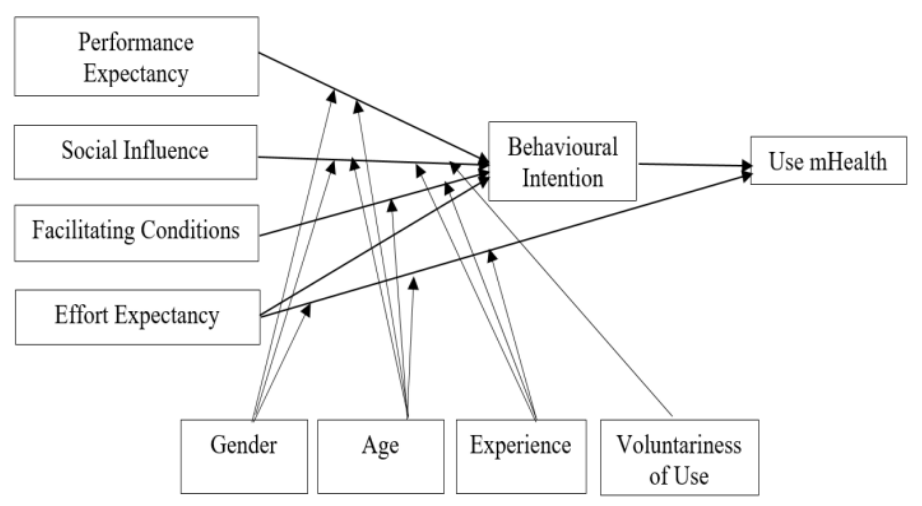

Fig. 1: Unified Theory of Acceptance and Use of Technology (UTAUT)

\section{A Conceptual Framework}

Although the proposed UTAUT model based on user acceptance can considerably explain the acceptance of technology applications, there is still a research gap to be completely fulfilled. From literature review and hypothesis development parts, adding potential factors to explain intention of use is necessary to lead to the achievement of research objectives to study factors influencing mHealth acceptance [51][52]. To study the effects of factors resulting in the use of mHealth in Thailand, this research aims to build a proposed model using the theory of UTAUT, SE, TA and PIIT which are potential factors needed to be applied for studying the acceptance of mHealth in Thailand as shown in Fig. 2.

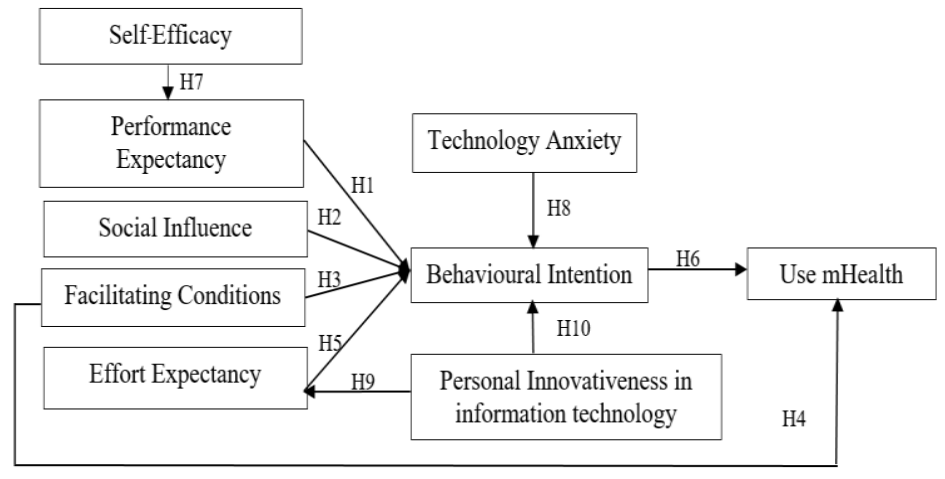

Fig. 2: Conceptual Framework

\section{Contributions and Further Study}

This research has an objective to generate an extended framework using UTAUT to study the factors affecting the technology acceptance, which can be used for user acceptance in mHealth. The ten hypotheses established above have been developed from the compilation of important theories of UTAUT, SE, TA and PIIT. This would provide more understanding potential factors that could be important to encourage using mHealth. Further research using quantitative analysis will be conducted by using questionnaires and statistical tools. Subsequently, structural equation model (SEM) has been used to validate the mHealth acceptance model in Thailand. 


\section{References}

[1] K. Grace, O'C. Yvonne, E. Emmanuel, N. Edmund, and H. Ciara, "A Ground-Up Approach to mHealth in Nigeria: A Study of Primary Healthcare Workers' Attitude to mHealth Adoption," Procedia Computer Science. 121, 2017, pp. 809-816.

[2] U. Varshney, "Mobile health: four emerging themes of research," Decis. Support Syst. 66, 2014, pp. 20-35.

[3] X. Zhang, X. Guo, K-H. Lai, F. Guo, C. Li, "Understanding gender differences in m-health adoption: a modified theory of reasoned action model," Telemed. e-Health. 2014, 20 (1): 39-46.

[4] R. Istepanian, H. S, E. Jovanov, and Y.T. Zhang, Guest. "Editorial Introduction to the Special Section on MHealth: Beyond Seamless Mobility and Global Wireless Health-Care Connectivity", IEEE Transactions on Information Technology in Biomedicine. 2004, 8 (4): 405-414.

[5] C. Free, G. Phillips, L, Felix, L, Galli, V. Patel, and P. Edwards, "The effectiveness of m-health technologies for improving health and health services: a systematic review protocol," BMC Res. Notes. 2010, 3 (1): pp. 250-257.

[6] K. Kallander, JK. Tibenderana, OJ. Akpogheneta, DL. Strachan, Z. Hill, AH. Ten Asbroek, L. Conteh, BR.

Kirkwood, SR. Meek,. "Mobile health (mHealth) approaches and lessons for increased performance and retention of community health workers in low- and middle-income countries: a review," J. Med. Internet Res. 2013, 15 (1): p.17.

[7] D. D. Luxton, R. A. McCann, N. E. Bush, M. C. Mishkind, and G. M. Reger, "MHealth for mental health: integrating smartphone technology in behavioral healthcare," Prof. Psychol. Res. Pract. 2011, 42 (6): pp.505-512.

[8] S. Kumar, W. J. Nilsen, A. Abernethy et al, "Mobile health technology evaluation: the mHealth evidence workshop," Am. J. Prev. Med. 45 (2), 2013, pp. 228-236, http://dx.doi.org/10.1016/j.amepre.2013.03.017.

[9] D. Ben-Zeev, M. S. Kaiser, C. J. Brenner et al, "Development and usability testing of FOCUS: a smartphone system for self-management of schizophrenia," Psychiatr. Rehabil. 2013, J. 36 (4): pp. 289 -296, http: //dx. doi. org/ 10.1037 /prj0000019.

[10] J. A. Cafazzo, M. Casselman, N. Hamming et al, "Design of an mHealth app for the self-management of adolescent type 1 diabetes: a pilot study," J. Med. Internet Res. 2012, 14 (3): p. 70, http://dx.doi.org/10.2196/jmir.2058.

[11] IMS Institute for Healthcare Informatics. Patient Apps for Improved Healthcare: From Novelty to Mainstream, 2013.

[12] World Health Organization. mHealth: New horizons for health through mobile technologies, 2011.

[13] A. Bavishi, Rapid Growth predicted for mHealth in Asia, 2015.

[14] Health Policy in Thailand. (Internet resource), Available from: http://www.searo.who.int/LinkFiles/On-going projects HP Tha-2006.pdf. 2006.

[15] A. Towse, A. Mills, V. Tangcharoensathien, "Learning from Thailand's health reforms," BMJ 328 January (7431), 2004, pp. 103-105.

[16] Information and Communication Technology Center, Ministry of Public Health's Information and Communication Technology Master Plan 2004-2006 (Thai Language) (Web page) 2004, Available from: www.moph.go.th/ict/data/MOPH ICTPlan.zip.

[17] D. Zurovac, O. A. Talisuna, W. R. Snow, Mobile phone text messaging: tool formalaria control in Africa, PLoS Med. 9, e1001176. 2012.

[18] T. Ahmed, G. Bloom, M. Iqbal, H. Lucas, S. Rasheed, L. Waldman, A.s. Khan, R. Islam, and A. Bhuiya, "E and M Health in Bangladesh: Opportunities and Challenges," IDS Evidence Report 60, Brighton: IDS, 2014.

[19] R. Hoque, G. Sorwar, "Understanding factors influencing the adoption of mHealth by the elderly: An extension of the UTAUT model," International Journal of Medical Informatics 101, 2017, pp. 75-84.

[20] E. Sezgin, Ö.-Y. Sevgi, Y. Soner, "Investigation of physicians' awareness and use of mHealth apps: A mixed method study," Health Policy and Technology 6, 2017, pp. 251-267. 
[21] V. Venkatesh, M. G. Morris, G. B. Davis, F. D. Davis, "User acceptance of information technology: toward a unified view," MIS Q. 2003, 27 (3).

[22] J. Jenifer, "Patients' intention to use online postings of ED wait time: A modified UTAUT model," International Journal of medical informatics. 112, 2018, pp. 34-39.

[23] N.M. Suki, N.M. Suki, "Detemining students' behavioural intention to use animation and storytelling applying the UTAUT model: The moderating roles of gender and experience level," The interantional Journal of Management Education. 15, 2017, pp. 528-538.

[24] T. J. Ami-Narh, and P. Williams, "A Revised UTAUT Model to Investigate E-health Acceptance of Health Professionals in Africa. Journal of Emerging Trends in Computing and Information Sciences," 2012,3 (10): pp.1383-1391.

[25] M. Anshari, M.N. Almunawar, "mHealth technology implication: shifting the role of patients from recipients to partners of care," in: S. Adibi (Ed.), mHealth Multidisciplinary Verticals, CRC Press, 2014, pp. 527-542, http://dx.doi.org/10. 1201/b17724-30.

[26] V. Venkatesh, J. Y .L. Thong, and X. Xu, "Consumer acceptance and use of information technology: extending the unified theory of acceptance and use of technology,” MIS Quartely, 2012, 36 (1): pp.157-178.

[27] V. Venkatesh, M. G. Morris, G. B. Davis, F. D. Davis, "User acceptance of information technology: toward a unified view," MIS Q. 2003, 27 (3): pp. 425-478.

[28] Pew Internet. 2010. Mobile Access, Available from: http://www.pewinternet.org/ /media/Files/Reports/2010/PIPMobileAccess2010.pdf (Accessed23.05.16).

[29] P. A. Nuq, B. Aubert, "Towards a better understanding of the intention to useeHealth services by medical professionals: the case of developing countries," Int. J. Healthcare Manage. 2013, 6 (4): pp. 217-236.

[30] C.P. Lin, B. Anol, "Learning online social support: an investigation of networkinformation technology based on UTAUT," CyberPsychol. Behav. 11, 2008, pp. 268-272.

[31] L. Xue, C. C. Yen, L. Chang, H. C. Chan, B. C. Tai, S. B. Tan, M. Choolani, “An exploratory study of ageing women's perception on access to health informatics via a mobile phone-based intervention," Int. J. Med. Inf. 81, 2012, pp. 637-648.

[32] M. Zhou, M. Herselman, A. Coleman, "Investigating Factor Determining the Use of the Clinical Care Module by Nurses Through the UTAUT Model. The Eighth International Conference on eHealth," Telemedicine and Social Medicine, 2016, pp. 186-191.

[33] T.A.M. Spil, and W. R. Schuring, "E-Health Systems Diffusion and Use: The Innovation, the User and the Use IT Model: The Innovation," Idea Group Inc (IGI), 2006.

[34] M. Wills, O. El-Gayar, and D. Benett, "Examining Healthcare Professionals' Acceptance of Electronic Medical Records Using UTAUT,” Issues in Information Systems. 2008, IX (2): pp. 396-401.

[35] Y. K. Dwivedi, M. A. Shareef, A. C. Simintiras, B. Lal, V. Weerakkody, "A generalised adoption model for services: A cross-country comparison of mobile health (m-health)," Government Information Quarterly 33, 2016, pp. 174-187.

[36] Or, Calvin, C.K.L. Karsh, , B.-T. Severston, T.V. Burke, L. J. Brown, R. L., and P. F. Brennan, "Factors affecting home care patients' acceptance of a web-based interactive self-management technology," Journal of the American Medical Informatics Association: JAMIA. 2011, 18 (1): pp. 51-9.

[37] J. Lu, Yao, J. E., C. S. Yu, "Personal innovativeness: social influences and adoption of wireless Internet services via mobile technology,” J. Strat. Inf. Syst. 14, 2005, pp. 245-268.

[38] M. J. Wills, O. F. El-Gayar, D. Bennett, “Examining healthcare professionals' acceptance of electronic medical records using UTAUT,” Issues Inf. Syst. 9, 2008, pp. 396-401.

[39] P. Akhtar, Z. Khan, S. Tarba, U. Jayawickrama, "The Internet of Things, dynamic data and information processing capabilities," and operational agility. Technol. Forecast. Soc, 2017b, http://dx.doi.org/10.1016/j.techfore, 04. 023. 
[40] G. Kabra, A. Ramesh, P. Akhtar, P., M. K. Dash, "Understanding behavioural intention to use information technology: Insights from humanitarian practitioners," Telematics and Informatics 34, 2017, pp. 1250-1261.

[41] E. M. Rogers, "Diffusion of Innovations [Internet]. In: Salwen MB, Stacks DW, editors. An integrated approach to communication theory and research" NY: Free Press; 1995, p. 519. (Health Behavior and Health Education: Theory,Research,and Practice; vol.65) Available from:(http://books.google.com/books?hl=en\&lr=\&id=v1ii4QsB7jIC\&pgis=1).

[42] R. Prasanna, T.J. Huggins, "Factors affecting the acceptance of information systems supporting emergency operations centres," Comput. Human Behav, 57, 2016, pp. 168-181.

[43] B. Kijsanayotin, S. Pannarunothai, S.M. Speedie, "Factors influencing healthinformation technology adoption in Thailand's community health centers:applying the UTAUT model," Int. J. Med. Inf. 78, 2009, pp. 404-416.

[44] J. Kim, and H.-A. Park, "Development of a health information technology acceptance model using consumers' health behavior intention," Journal of medical Internet research. 2012, 14 (5): p.133.

[45] S. Lim, L. Xue, C.C. Yen, L. Chang, H. C. Chan, B. C. Tai, H. L. Duh, and M. Choolani, "A study on Singaporean women's acceptance of using mobile phones to seek health information," International journal of medical informatics, 2011, 80 (12): pp.189-202.

[46] X. Guo, Y. Sun, N. Wang, Z. Peng, and Z. Yan, "The dark side of elderly acceptance of preventive mobile health services in China," Electron. Mark. 2013, 23 (1): pp. 49-61.

[47] B. Hasan, M. U. Ahmed, "A path analysis of the impact of application-specific perceptions of computer selfefficacy and anxiety on technology acceptance," Journal of Organizational and End User Computing. 2010,22 (3): pp. 82-95.

[48] M. Igbaria, J. Iivari, “The effects of self-efficacy on computer usage,” Omega. 1995, 23 (6): pp. 587-605.

[49] Y. Sun, N. Wang, X. Guo, Z. Peng, "Understanding the acceptance of mobilehealth services: a comparison and integration of alternative models," J.Electron. Commerce Res. 2013, 14 (2): pp. 183-200.

[50] E. M. Roger, The diffusion of innovation, The Free Press, New York, 1995.

[51] I. Im, S. Hong, M. S. Kang, "An international comparison of technology adoption Testing the UTAUT models," Information \& Management 48, 2011, pp. 1-8.

[52] B. P. Mirjana, C. Amerana, and Z. Jovana, "Technology Acceptance Model for Business Intelligence Systems: Preliminary Research,” Procedia Computer Sciences 100, 2016, pp. 995 - 1001. 